\title{
ĐẶC ĐIỂM HÌNH ẢNH CộNG HƯởNG TỪ CỦA UNG THƯ LƯỡI PHẦN DI ĐÔ̂NG VÀ̀ GIÁ TRI CỦA CÔ̂NG HƯỞNG TỪ TRONG CHẨN ĐOÁN GIAI ĐOẠN
}

\section{TÓM TẮT.}

Mục tiêu: Đặc điểm hình ảnh của ung thư lưỡi trên phim cộng hưởng từ và giá trị của cộng hưởng từ trong đánh giá giai đoạn bệnh. Đối tượng nghiên cứu: Mô tả tiến cứu gồm 52 bệnh nhân được chẩn đoán ung thư lưỡi và được chụp CHT, được điều trị tại bệnh viện $\mathrm{K}$ cớ sở Tân Triều từ tháng 5 nằm 2018 đển tháng 7 năm 2019. Kết quả: Trên T1, phần lớn u có đặc điểm giảm tín hiệu trước tiêm $(67,4 \%)$; sau tiêm tỷ lê tăng tín hiêu là 96,2\%. Có tới 96,2\% khối u tăng tín hiệu trên STIR. Phần lớn khối u là không đồng nhất chiếm tỷ lệ $65,4 \%$. So sánh giai đoạn $T$ trên $C H T$ và $\mathrm{MBH}$ bằng chỉ số Kappa thu được giá trị $\mathrm{K}=0,645$. Ngoài ra, CHT có độ đặc hiệu cao trong chẩn đoán di căn hạch bach huyểt $(96 \%)$, giá trị dự báo âm tính là 92,3\%. Kết luận: Hình ảnh ung thư lưỡi trên phim cộng hưởng từ thường không đồng nhất, giảm tín hiệu trên T1 bắt thuốc sau tiêm, tăng tín hiệu trên STIR. Cộng hưởng từ là phương pháp rất có giá trị trong chẩn đoán giai đoạn bệnh ung thư lưỡi di động.

Tư khóa: ung thư khoang miệng, ung thư lưỡi di động, cộng hưởng từ, chẩn đoán giai đoạn

\section{SUMMARY \\ IMAGING CHARACTERISTICS AND ASSESSING VALUES OF MRI IN THE STAGING OF MOBILE TONGUE CANCER}

Objectives: Describing imaqing characteristics and assessing values of MRI in the staging of mobile tongue cancer. Patients and methods: 52 patients with tongue tumors were selected to be in a descriptive study, in which they urere diagnosed and had pathology results from May 2018 to July 2019 at Vietnam National Cancer Hospital. Results: On T1, $67.4 \%$ patients showed low signal and $96.2 \%$ patients showed a contrast enhancement. $96.2 \%$ patients revealed hyperintense on STIR. A major of patients showed nonhomogeneous features on MRI (65.4\%). The Cohen's Kappa score of 0.645 had a good correlatiom between MRI results and histopathology in distinguishing T-staging of tongue tumour. Moreover, the sensitivity and negative predicted value of MRI on $\mathrm{N}$ staging was $96 \%$ and $92.3 \%$, respectively. Conclusion: Most patients with mobile tongue cancer showed nonhomogeneous, low signal and contrast

${ }^{1}$ Bệnh viện $K$ Trung Ưong

2Trường Đai hoc Y Hà Nội

Chịu trách nhiệm chính: Lê Văn Quảng

Email: Lequang@hmu.edu.vn

Ngày nhận bài: 19.11.2020

Ngày phản biên khoa học: 7.01.2021

Ngày duyệt bài: 21.01.2021

\section{Lê Văn Quảng ${ }^{1,2}$, Lê Thị Hồng Phượng1, Ngô Quốc Duy ${ }^{1}$, Bùi Văn Giang1,2}

enhancement on T1, revealed hyperintense on STIR. MRI was a valuable method on staging mobile tongue cancer.

Key words: oral cavity cancer, mobile tongue cancer, MRI, staging,

\section{I. ĐẶT VẤN ĐỀ}

Ung thư khoang miệng (UTKM) là một trong những bệnh phổ biến, chiếm khoảng 30 - 40\% các ung thư của vùng đâu cổ. Theo GLOBOCAN 2018, hằng năm có khoảng 354.000 ca mới mắc và có 177.000 ca tử vong do ung thư khoang miệng. Trong đó ung thư lưỡi phân di động là hay gặp nhất [1].

Chẩn đoán giai đoạn ung thư lưỡi có vai trò rất quan trọng trong việc lên kế hoạch điêuu trị cũng như tiên lượng bệnh nhân. Trong các phương tiện đánh giá mức độ xâm lấn tại chố, cộng hưởng từ là phương pháp có giá trị nhất [2].

Hiện nay, tại Việt Nam còn rất ít nghiên cứu đặc điểm hình ảnh của ung thư lưỡi di động trên phim cộng hưởng từ và giá trị của cộng hưởng từ trong việc đánh giá giai đoạn bệnh. Do vậy, chúng tôi tiến hành nghiên cứu: "Đặc điểm hình ảnh của ung thư lưỡi trên phim cộng hưởng tư và giá trị của cộng hưởng từ trong đánh giá giai đoạn bệnh."

\section{II. ĐỐI TƯỢNG VÀ PHƯƠNG PHÁP NGHIÊN CỨU}

2.1. Đối tượng nghiên cứu. Gồm 52 bệnh nhân được chẩn đoán ung thư lưỡi và được chụp CHT, được điều trị tại bệnh viện $\mathrm{K}$ cơ sở Tẩn Triều từ tháng 5 năm 2018 đến tháng 7 năm 2019.

2.2. Tiêu chuẩn lựa chọn bệnh nhân. Các bệnh nhân được chẩn đoán ung thư lưỡi, được chụp $\mathrm{CHT}$, được điêuu trị tại bệnh viện $\mathrm{K}$

2.3. Tiêu chuẩn loại trừ. Giải phẫu bệnh không phải là ung thư biểu mô vảy không sừng hoá. Đã được phẩu thuật cắt u hoặc lấy hạch cổ trước đó.

2.4. Phương pháp nghiên cứu: Mô tả cắt ngang tiến cứu

2.5. Phương tiện nghiên cứu. Máy $\mathrm{CHT}$ 1.5 Tesla tại bệnh viện $\mathrm{K}$ cơ sở Tân Triều

2.6. Phân tích số liệu. Sử dụng phương pháp thống kê toán học trong y học với phân mềm SPSS 20.0 


\section{KẾT QUẢ NGHIÊN CỨU}

2.1. Đặc điểm ung thư lưỡi trên cộng hưởng từ

Bảng 1: Đặc điểm tín hiệu u trên chuỗi xung của T1 trước và sau tiêm thuốc cản quang

\begin{tabular}{|c|c|c|c|c|}
\hline \multirow{2}{*}{ Tín hiệu } & \multicolumn{2}{|c|}{ Trước tiêm } & \multicolumn{2}{c|}{ Sau tiêm } \\
\cline { 2 - 5 } & $\begin{array}{c}\text { Số } \\
\text { lượng }\end{array}$ & $\begin{array}{c}\text { Tý lệ } \\
\%\end{array}$ & $\begin{array}{c}\text { Số } \\
\text { lượng }\end{array}$ & $\begin{array}{c}\text { Tỷ lệ } \\
\%\end{array}$ \\
\hline Tăng tín hiệu & 0 & 0 & 50 & 96,2 \\
\hline Giảm tín hiệu & 35 & 67,4 & 0 & 0 \\
\hline Đồng tín hiệu & 17 & 32,6 & 2 & 3,8 \\
\hline
\end{tabular}

Nhận xét: Về đặc điểm tín hiệu u trên chuồi xung của $\mathrm{T} 1$, trước tiêm phần lớn u giảm tín hiệu với tỷ lệ là $67,4 \%$; tiếp đến là đồng tín hiệu với $32,6 \%$. Ngược lại, sau tiêm 96,2\% khối u tăng tín hiệu.

Bảng 2: Đặc điểm tín hiệu u trên chuỗi xung STIR

\begin{tabular}{|c|c|c|}
\hline Đặc điếm tín hiệu & Số lượng & Tỷ lệ \% \\
\hline Tăng tín hiệu & 50 & 96,2 \\
\hline Giảm tín hiệu & 0 & 0 \\
\hline Đồng tín hiệu & 2 & 3,8 \\
\hline
\end{tabular}
STIR.

Bảng 3: Đăc điểm tính chât của UTL trên CHT

\begin{tabular}{|c|c|c|}
\hline Tính chất & Số lượng & Tỷ lệ \% \\
\hline Đồng nhất & 18 & 36 \\
\hline Không đồng nhất & 32 & 64 \\
\hline
\end{tabular}

Nhận xét: Phần lớn các khối u là không đồng nhất, chiếm 64 (\%).

Bảng 4: Đường kính lớn nhất u trên CHT

\begin{tabular}{|c|c|c|}
\hline Kích thước u & Số lượng & Tỷ lệ\% \\
\hline$\leq 2 \mathrm{~cm}$ & 13 & 25 \\
\hline $2<\mathrm{u} \leq 4 \mathrm{~cm}$ & 19 & 36,5 \\
\hline$>4 \mathrm{~cm}$ & 20 & 38,5 \\
\hline
\end{tabular}

Nhận xét: Đường kính lớn nhất của u trung bình đo được là $32,8 \pm 18,27 \mathrm{~mm}$; trong đó, u có đường kính lớn nhất từ trên $4 \mathrm{~cm}$ chiếm tỷ lệ cao nhất với $38,5 \%$; tiếp đến là u từ 2 đến $4 \mathrm{~cm}$ $(36,5 \%)$ và dưới $2 \mathrm{~cm}(25 \%)$

Bảng 5: Độ sâu xâm lấn của u trên CHT

\begin{tabular}{|c|c|c|}
\hline $\begin{array}{c}\text { Độ sâu xâm lấn } \\
\text { (DOI) }\end{array}$ & Số lượng & Tỷ lệ \% \\
\hline Dưới 5mm & 5 & 9,7 \\
\hline Từ 5 đến 10 mm & 10 & 19,2 \\
\hline Từ 10 đến $20 \mathrm{~mm}$ & 15 & 28,8 \\
\hline Trên 20mm & 22 & 42,3 \\
\hline
\end{tabular}
Max 47mm

Nhận xét: Về độ sâu xâm lấn của khối u (DOI) đo được trên CHT, DOI trung bình là 18,7 $\pm 10,6 \mathrm{~mm}$; DOI trên $20 \mathrm{~mm}$ chiếm tỷ lệ cao nhất là $42,3 \%$, tiếp đến là từ 10 đến $20 \mathrm{~mm}$ $(28,8 \%)$ và từ $5 \mathrm{~mm}$ đến $10 \mathrm{~mm}(19,2 \%)$, và $\mathrm{DOI}$ dưới $5 \mathrm{~mm}$ chỉ chiếm 9,7\%.

Bảng 6: Đặc điểm của hạch trên CHT

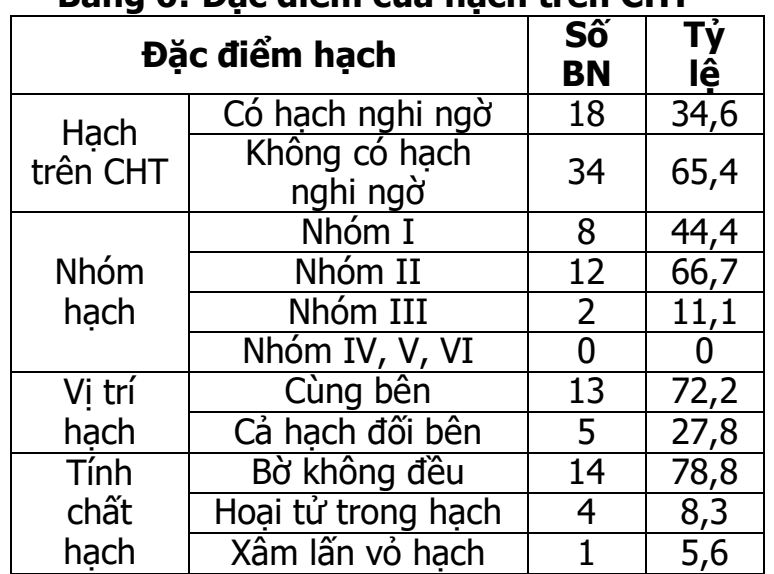

Nhận xét: Trong 52 bệnh nhân nghiên cứu có 18 bệnh nhân có hạch nghi ngờ thứ phát trên $\mathrm{CHT}$, chiếm tỷ lệ $34,6 \%$. Vị trí hạch hay gặp là nhóm II với $66,7 \%$, nhóm I với $44,4 \%$, và nhóm III chỉ có $11,1 \%$. Đa số các hạch ở cùng bên với tổn thương trong $72,2 \%$ trường hợp, và có $27,8 \%$ bệnh nhân có hạch cả hai bên. Hầu hết các hạch có bờ không đều, chiếm tỷ lệ $78,8 \%$. Có 4 BN có hạch hoại tử, chiếm 8,3\%. Chỉ có 1 $\mathrm{BN}$ có xâm lấn vỏ hạch trên $\mathrm{CHT}$, chiếm $5,6 \%$.

Bảng 7: Giai đoạn của hạch trên CHT

\begin{tabular}{|c|c|c|}
\hline Giai đoạn hạch & Tân số & Tỷ lệ \% \\
\hline N0 & 34 & 65,4 \\
\hline N1 & 12 & 23,1 \\
\hline N2a & 0 & 0 \\
\hline N2b & 0 & 0 \\
\hline N2c & 5 & 9,6 \\
\hline N3a & 0 & 0 \\
\hline N3b & 1 & 1,9 \\
\hline
\end{tabular}

Nhận xét: Có đến 65,4\% đối tượng nghiên cứu không có di căn hạch; tỷ lệ di căn ở mức độ $\mathrm{N} 1$ chiếm tỷ lệ $23,1 \%$ và $\mathrm{N} 2 \mathrm{c}$ chiếm $9,6 \%$, N3b chiếm 1,9\%.

Bảng 8: Môi liên quan giữa độ sâu xâm lấn cứa khối u và mức độ di căn hạch bạch huyết trên CHT

\begin{tabular}{|c|c|c|c|c|}
\hline GĐ di & \multicolumn{2}{|c|}{ Độ sâu xâm lấn của u } & \\
\cline { 2 - 5 } $\begin{array}{c}\text { cân } \\
\text { hạch }\end{array}$ & $<5 \mathrm{~mm}$ & $5-10 \mathrm{~mm}$ & $10-20 \mathrm{~mm}$ & $>20 \mathrm{~mm}$ \\
\hline N0 & $5(100)$ & $10(100)$ & $13(86,7)$ & $6(27,3)$ \\
\hline N1 & 0 & 0 & $2(13,3)$ & $10(45,4)$ \\
\hline N2 & 0 & 0 & 0 & $5(22,7)$ \\
\hline N3 & 0 & 0 & 0 & $1(4,6)$ \\
\hline Tống & $5(100)$ & $10(100)$ & $15(100)$ & $22(100)$ \\
\hline
\end{tabular}

Nhận xét: DOI càng cao mức độ di căn hạch bạch huyết trên $\mathrm{CHT}$ càng lớn. Đối với nhóm có DOI trên $20 \mathrm{~mm}$ phần lớn $\mathrm{BN}$ đều di căn hạch (GĐ N1 45,4\% và N2 lên đến $22,7 \%$ và N3 là 4,6\%) 
2.2. Giá trị cộng hưởng từ trong chẩn đoán giai đoạn. Trong số 52 bệnh nhẫn trong nghiên cứu, có 28 bệnh nhân được phẫu thuật cắt nửa lưới kèm vét hạch cổ, từ đó đánh giá được chính xác pTNM và DOI sau phẫu thuật. Qua đó cũng đánh giá được giá trị của cộng hưởng từ trong chẩn đoán giai đoạn bệnh.

Bảng 9: Mối liên quan giữa giai đoạn T trên CHT và giai đoạn $T$ trên MBH

\begin{tabular}{|c|c|c|c|c|c|c|}
\hline \multirow{2}{*}{ Giai đoạn T trên CHT } & \multicolumn{7}{|c|}{ Giai đoạn T trên MBH } \\
\cline { 2 - 7 } & T1 & T2 & T3 & T4a & T4b & Tống \\
\hline Tx & 2 & 0 & 0 & 0 & 0 & 2 \\
\hline T1 & 1 & 1 & 0 & 0 & 0 & 2 \\
\hline T2 & 2 & 9 & 0 & 0 & 0 & 11 \\
\hline T3 & 0 & 3 & 6 & 1 & 0 & 10 \\
\hline T4a & 0 & 0 & 1 & 2 & 0 & 3 \\
\hline T4b & 0 & 0 & 0 & 0 & 0 & 0 \\
\hline Tống & $\mathbf{5}$ & $\mathbf{1 3}$ & $\mathbf{7}$ & $\mathbf{3}$ & $\mathbf{0}$ & $\mathbf{2 8}$ \\
\hline
\end{tabular}

Nhận xét: So sánh giai đoạn $T$ trên $\mathrm{CHT}$ và $\mathrm{MBH}$ bằng chỉ số Kappa thu được giá trị $\mathrm{K}=0,645$, có nghĩ̃a là kết quả đánh giá giai đoạn T trên $\mathrm{CHT}$ và $\mathrm{MBH}$ có sự đồng thuận cao.

Bảng 10: Giá trị của CHT trong chẩn đoán di căn hạch

\begin{tabular}{|c|c|c|c|}
\hline CHT MBH & $\begin{array}{c}\text { Có di căn } \\
\text { hạch }\end{array}$ & $\begin{array}{l}\text { Không di } \\
\text { căn hạch }\end{array}$ & Tổng \\
\hline Có di căn hạch & 1 & 1 & 2 \\
\hline Không di căn hạch & 2 & 24 & 26 \\
\hline Tống & 3 & 25 & 28 \\
\hline
\end{tabular}

Nhận xét: Độ đặc hiệu $=96 \%$, giá trị dự báo âm tính $=92,3 \%$

\section{BÀN LUẬN}

3.1. Đặc điểm hình ảnh ung thư lưỡi trên CHT

\section{U nguyên phát}

Trên hình ảnh T1W. Trước tiêm phần lớn u có đặc điểm giảm tín hiệu $(67,4 \%)$; ngược lại sau tiêm tỷ lệ tăng tín hiệu $(96,2 \%)$. Kết quả này khá tương tự với nghiên cứu của Nguyền Văn Hương với đặc điểm tín hiệu u trên xung T1W trước tiêm phần lớn là giảm tín hiệu so với cơ $(79,6 \%)[3]$.

Trên chuỗi xung STIR. Kết quả nghiên cứu cho thây $96,2 \%$ khối u là tăng tín hiệu. Có 3,8\% trường hợp trong nghiên cứu không phát hiện được tổn thương. Kết quả này khá tương tự với nghiên cứu trước đó về vai trò của $\mathrm{CHT}$ với đặc điểm trên chuỗi xung STIR khối u tăng tín hiệu so với cơ xung quanh chiếm tỷ lệ $81,4 \%$ và có 13,6\% là tín hiệu hỗn hợp [3]. Theo nghiên cứu của Nguyễn Trung Kiên tỳ lệ khối u có tăng tín hiêuu trên STIR chiếm 94,9\%[4]. Chuỗi xung STIR rất nhạy để phát hiện tổn thương; đặc biệt CHT rất hữu ích để phân biệt tổn thương u hay tổn thương viêm nhiếm ở vùng khoang miêng và hỗ trơ chắt chẽ cho quá trình điều trị cũng như theo dõi sau điều trị ung thư. Bên cạnh đó, chuỗi xung STIR nhạy hơn chuỗi xung T2W trong việc phát hiện các khối u lưỡi có kích thước nhỏ [5].
Tính chất và mức đô xâm lấn của khối u. Kết quả nghiên cứu cho thấy phần lớn các khối u là không đồng nhất chiếm tỳ lệ $65,4 \%$, có $75 \%$ là khu trú tại lưỡi và $26,9 \%$ có xâm lấn sàn miệng, 3,8\% xâm lấn xương hàm (xương hàm trên, xương hàm dưới), 9,6\% xâm lấn xuống thanh quản - hạ họng. $\mathrm{CHT}$ là một công cụ rất hữu ích để phân tích các chi tiết giải phẫu của các cấu trúc trong khoang miệng và cả các cấu trúc lân cận. Sự phân giải mồ mềm rất tốt của CHT giúp dễ dàng đánh giá sự xâm lấn của khối u vào các cấu trúc xung quanh. CHT cung cấp thông tin về sự xâm lấn đáy lưỡi, sàn miệng và đặc biệt là khi khối u phát triển xuống phẩn hầu họng, rất khó nhìn thấy trên CLVT.

Theo nghiên cứu của Li et al [6], đưa ra rằng CLVT có độ nhạy $72 \%$ với độ đặc hiệu $90 \%$ và MRI có độ nhạy $78 \%$ và độ đặc hiệu $83 \%$ trong việc đánh giá xâm lấn xương hàm dưới. Nghiên cứu khác của Nae et al cho rằng việc phối hợp CLVT và $\mathrm{CHT}$ có độ nhạy $100 \%$ và độ đặc hiệu $72 \%$ trong việc đánh giá xâm lấn xương hàm dưới của ung thư biểu mô vùng khoang miệng[7].

Đặc điểm của hạch trên CHT

Vể vị trí hạch trên CHT. Vị trí hạch hay gặp là nhóm II với $66,7 \%$, nhóm I với $44,4 \%$, và nhóm III chỉ có $11,1 \%$. Đa số các hạch ở cùng bên với tổn thương trong $72,2 \%$ trường hợp, và có $27,8 \%$ bệnh nhân có hạch cả hai bên. Kết quả thu được phù hợp với các nghiên cứu trước đây. Với hạch hay gặp nhất là hach dưới cằm, dưới hàm và cảnh cao (hạch thuộc nhóm I và II). Trong đó, hạch nhóm II có tần suất di căn cao nhất, sau đó đến nhóm I, III và IV. Theo nghiên cứu của Nguyễn Trung Kiên cho thấy phần lớn hạch thuộc nhóm I và II với tỷ lệ lần lượt là $40 \%$ và $51,1 \%$ [4]. 
Về giai đoạn của hạch trên CHT. Kết quả nghiên cứu cho thấy có đến $65,4 \%$ đối tượng nghiên cứu không có di căn hạch; tỷ lệ di căn ở mức độ $\mathrm{N} 1$ chiếm tỳ lệ $23,1 \%$ và N2c chiếm $9,6 \%$, N3b chiếm $1,9 \%$. Kết quả này có sự khác biệt nhỏ so với nghiên cứu tiến hành tại Nhật Bản (2008) với tỷ lệ hạch ở giai đoạn No chiếm tỷ lệ cao nhất với $74 \%$ và giai đoạn N1-3 chỉ chiếm $26 \%$ [8]. Kết quả này cho thấy rằng các bệnh nhân trong nghiên cứu của chúng tôi được phát hiên bênh ở giai đoan khá muôn - khi đã có di căn hạch. Như vậy, việc phát hiện bệnh ở giai đoạn muộn ảnh hưởng rất nhiều đến kết quả điêu trị cũ̃ng như chất lượng cuộc sống và thời gian sống thêm của bệnh nhân.

Về mối liên quan giữa độ sâu xâm lấn của khối u và giai đoạn hạch trên $\mathrm{CHT}$. Kết quả nghiên cứu cho thây độ sâu xâm lấn u càng cao mức độ di căn hạch bạch huyết trên $\mathrm{CHT}$ càng lớn. Cụ thể, với độ sâu xâm lấn u dưới 5 $\mathrm{mm}$ và từ 5 đến $10 \mathrm{~mm}$ đều tương ứng với $100 \%$ không di căn hạch N0; tỷ lệ này giảm xuống $86,7 \%$ đối với u có độ sâu xầm nhập từ 10 đến $20 \mathrm{~mm}$ và có $13,3 \%$ hạch ở giai đoạn N1; đối với nhóm có độ sâu xâm lấn trên $20 \mathrm{~mm}$ phần lớn hạch ở giai đoạn N1 với 45,4\% và tỷ lệ ở N2 lên đến $22,7 \%$ và N3 là 4,6\%. Một nghiên cứu chỉ ra rằng trong nhóm các khối u có độ sâu dưới $5 \mathrm{~mm}$ tỷ lệ di căn hạch cổ là $0 \%$, trong khi nhóm có độ sâu trên $5 \mathrm{~mm}$ tỷ lê di căn hach cổ là $65 \%[9]$. Theo nghiên cứu của Shitani khẳng định độ sâu xâm lấn là một yếu tố quan trọng trong tiên lượng khối u nguyên phát đặc biệt trong sự liên quan với di căn hạch vùng cổ.

3.2. Giá trị cộng hưởng từ trong chẩn đoán giai đoạn

Vai trò của CHT trong đánh giá giai đoạn T của khối u. So sánh giai đoạn $\mathrm{T}$ trên $\mathrm{CHT}$ và $\mathrm{MBH}$ bằng chỉ số Kappa thu được giá trị $\mathrm{K}=$ 0,645 có nghĩa là kết quả đánh giá giai đoạn $T$ trên $\mathrm{CHT}$ và $\mathrm{MBH}$ có sự đồng thuận cao. Theo $\mathrm{NC}$ của Singh và cộng sự kết quả này $\mathrm{K}=0,79$. Kết quả này cũng phù với NC của Zeng et al [5]. Nghiên cứu của chúng tôi cho thấy CHT là một phương tiện thích hợp cho đánh giá các khối u ác tính vùng khoang miệng, trong việc đánh giá độ sâu xâm lấn của khối u ở giai đoạn $T$, cho thấy sự đồng thuận cao với kết quả MBH.

Vai trò CHT trong đánh giá giai đoạn hạch. Kết quả nghiên cứu cho thấy CHT có độ đặc hiệu cao trong chẩn đoán di căn hạch bạch huyết $(96 \%)$. Giá trị dự báo âm tính là $92,3 \%$. Do trong 28 bệnh nhân phẫu thuật, kết quả $\mathrm{MBH}$ thu được chỉ có 3 trường hợp có di căn hạch, nên trong nghiên cứu này chúng tôi chỉ tính toán đến độ đặc hiệu và giá trị dự báo âm tính của $\mathrm{CHT}$ trong chẩn đoán. Kết quả này tương đối phù hợp với kết quả nghiên cứu của tác giả Nguyễn Trung Kiên, giá trị CHT trong chẩn đoán hạch di căn với độ đặc hiệu là $90,2 \%$ [4]. Theo Jun Ook và cộng dự, giá trị chẩn đoán di căn hạch trên CHT có độ nhạy 83,3\%, độ đặc hiệu là $68 \%$, giá trị dự báo dương tính là $71,4 \%$ và giá trị dự báo âm tính là $81 \%$. Độ đặc hiệu và giá trị dự báo âm tính trong nghiên cứu của chúng tôi cao hơn, có thể giải thích điều này do cỡ mẫu nghiên cứu còn nhỏ (đánh giá trên 28 bệnh nhân có phẫu thuật nạo vét hạch toàn bộ - chủ yếu là các bệnh nhẩn giai đoạn sớm).

\section{KẾT LUÂ̂N}

Hình ảnh ung thư lưỡi trên phim cộng hưởng từ thường không đồng nhất, giảm tín hiệu trên T1 bắt thuốc sau tiêm, tăng tín hiệu trên STIR. Cộng hưởng từ là phương pháp rất có giá trị trong chẩn đoán giai đoạn bệnh ung thư lưỡi di động.

\section{TÀI LIÊU THAM KHẢO}

1. Bray F, Ferlay J, Soerjomataram I, et al (2018). Global cancer statistics 2018: GLOBOCAN estimates of incidence and mortality worldwide for 36 cancers in 185 countries. CA Cancer J Clin, 68(6): 394-424

2. Kirsch C. (2007). Oral Cavity Cancer. Topics in magnetic resonance imaging: TMRI, 18, 269-80.

3. Nguyển Văn Hương và Đoàn Văn Dũng (2015). Nghiên cứu đắc điểm hình ảnh trên MRI 3.0 Tesla trong bệnh lý u vùng khoang miệng và hầu họng trên xướng móng tại Bệnh viện Uning thư Đà Nằng. Điên Quang Viêt Nam, 21(8), p. 44-51.

4. Nguyễn Trung Kiên (2015). Nghiên cứu đặc điêm hình ảnh và giá trị của cộng hưởng từ trong chẩn đoán ung thư lưỡi. Luận văn thạc sỹ y học.

5. Zeng $H_{.}$, Liang $C_{.}$, Zhou $Z$. et al. (2003). [Study of preoperative MRI staging of tongue carcinoma in relation to pathological findings]. Di Yi Jun Yi Da Xue Xue Bao, 23(8), 841-843.

6. Li C., Men Y., Yang W. et al. (2014). Computed tomography for the diagnosis of mandibular invasion caused by head and neck cancer: a systematic review comparing contrast-enhanced and plain computed tomography. J Oral Maxillofac Surg, 72(8), 1601-1615.

7. Nae A., O'Leary G., Feeley L. et al. (2019). Utility of CT and MRI in assessment of mandibular involvement in oral cavity cancer. World J Otorhinolaryngol Head Neck Surg, 5(2), 71-75.

8. Okura M., Iida S., Aikawa T. et al. (2008). Tumor thickness and paralingual distance of coronal MR imaging predicts cervical node metastases in oral tongue carcinoma. AJNR Am J Neuroradiol, 29(1), 45-50.

9. Hoang J. K, J. Vanka, B. J. Ludwig, and et al (2013). Evaluation of cervical lymph nodes in head and neck cancer with CT and MRI: tips, traps, and a systematic approach. AJR Am J Roentgenol, 200(1), p. W17-25. 